\title{
L1 Thinking in Reading Process of Chinese College Students at Different Levels of English Proficiency
}

\author{
Tian Tian \\ School of Foreign Languages and Cultures, Beijing Wuzi University, Beijing, China \\ Email address: \\ tiantian@bwu.edu.cn \\ To cite this article: \\ Tian Tian. L1 Thinking in Reading Process of Chinese College Students at Different Levels of English Proficiency. English Language, \\ Literature \& Culture. Vol. 5, No. 4, 2020, pp. 154-158. doi: 10.11648/j.ellc.20200504.15
}

Received: November 20, 2020; Accepted: December 8, 2020; Published: December 22, 2020

\begin{abstract}
The paper adopts think-aloud method to record the thinking process of Chinese college students of different levels when they are reading English materials. The think-aloud protocols are transcribed, and the L1 thinking in their reading process is analyzed. The results are as follows: Readers at different levels apply L1 thinking in their L2 reading process to deal with vocabulary and sentence in different ways. Readers in low-level and intermediate-level group rely heavily on L1 to deal with word meaning because of the limitation of their vocabulary yet readers in advanced-level group tend to use more L1 to associate semantic meaning in the process of L2 reading. Participants in advanced-level group usually read several of sentences and skim or scan information which is regard as not useful and import while participants in low-level and intermediate-level group usually read almost all the sentences and try to comprehend all of them regardless of their importance. In light of the findings generated by the study, teachers may have different perspectives while dealing with students' reading activities. Since L1 thinking generally exists in the process of L2 reading, we should pay more attention to how to guide students to utilize L1 facilitating reading according to different students.
\end{abstract}

Keywords: L1 Thinking, L2 Reading, Think-aloud Protocols, Different Levels of English Proficiency

\section{Introduction}

Nowadays, researchers have come to an agreement that reading a second language (L2) text is not considered as a monolingual event: while they are reading, L2 readers have access to their native language all the time [1-3].

L2 reading is a more complicated process, in which it involves reading in a foreign language. When students read in L2, they have two languages (i.e., L1 and L2) at their disposal. College students usually have some knowledge of reading and reading strategies, but their linguistic knowledge of L2 is usually limited. L2 reading is not a passive process, but rather an active one; the L2 reader is seen as a cognitively active learner and it is seen that an effective reader reads strategically [4]; and use of L1 and TL should be seen as complementary [5].

However, the position of L1 in the L2 learning still remains unclear. The assumption of avoiding L1 use has been at the core of certain foreign language learning and teaching methods such as natural approach, total physical response and so on. In their opinion, if learners make use of L1 when processing an L2 task, L1 will impede SLA and affect L2.
Yet there have been studies which have examined the influence of L1 thinking on L2 reading, and the results tend to go against this belief. Kern discovers that L1 thinking facilitates L2 reading to a certain degree [6].

As a source of data for understanding the use of language, verbal report was a valuable and a thoroughly reliable source of information about cognitive process if the data was elicited with care and interpreted with full understanding of the circumstances under which they were obtained [7]. A wide variety of protocol data has shown that verbalizing thinking processes does not deform participants' natural cognitive processing.

The thesis intends to adopt think-aloud protocols to read English texts. The analysis of the think-aloud protocols aimed to figure out L1 thinking in L2 reading process when college students at different levels read the same English materials.

\section{Literature Review}

\subsection{L1 Thinking and Think-aloud Protocols}

It is widely agreed that L1 thinking is inevitable for L2 
learners in the process of learning another language. As Stern observed, the L1-L2 connection is an indisputable fact of life [5]. Consequently, L1 thinking has been viewed from the cognitive-psychological perspective [8] as a "strategic transfer" [9] by L2 Learners for developing and using their inter-language. The issue of L1 thinking in the ESL class is, to a certain extent, no longer a contentious one [10-11]. Auerbach argued that the "use of students' linguistic resources can be beneficial at all levels of ESL [10]." Similarly, Cook reminded teachers that whether they want it to be there or not, the L1 is ever present in the minds of their L2 learners [2].

Developed from the older introspection method, the think aloud method was rooted in the psychological research, which studies the events that take place in human consciousness. Matsumoto explained that think-aloud is a data collection method whereby informants are asked to say "what they are thinking and doing (i.e., everything that comes to mind) while performing a task [12]." Applied particularly to the area of reading, think-aloud can be seen as the reader's verbalization of his or her mental processes while engaged in reading.

\subsection{Theoretical Background}

In the 1920s, Russian psychologist Lev Vygotsky makes some claims about the relationship between language and thought. Vygotsky proposed that speech and thought have different ontogenetic roots. To Vygotsky, a clear understanding of the interrelations between thought and language is necessary for the understanding of intellectual development [13].

Cummins claims that there is a common operating system that exists across an individual's two (or more) language systems [14]. That is, on the surface, an individual may appear to have two distinct languages. Below the surface, however, there is an operating system that is shared by both languages. His theory is responsible for the functioning of languages in a bilingual's mind. Cummins proposed the interdependence hypothesis maintaining that second language acquisition is influenced greatly by the degree to which the first language is developed. He states this as "to the extent that instruction through a minority language is efficiency to the majority language will occur given adequate exposure and motivation to learn the language" [15]. He claims that L1 reading ability transfers to L2 reading and there is always a relationship between $L 1$ and $L 2$ reading.

\subsection{Related Studied on L1 in L2 Learning}

Think-aloud method is one of the common measures to study the data in psychology and cognitive science; it is applied widely in all the foreign language teaching and learning study and has become a mature study method gradually. It plays an important role in L2 reading study.

Comparatively speaking, there have been fewer studies on L1 use in L2 reading. Kern, whose study is one of the few that examines the language of thought used by L2 learners in comprehending L2 text, looks upon the role of translation as a cognitive strategy in the $\mathrm{L} 2$ reading comprehension process [6]. Guo and Liu propose the concept of "L1 involvement" on the basis of their empirical study of L1 use in the L2 writing process [16]. They find that L1 is actively involved in the writing process. Horiba investigated L2 learners' reading comprehension process by using think-aloud protocols [17]. The participants were divided into four groups: the participants in the first group were learners who learned Japanese with moderate-level proficiency; the second group were learners with high-level proficiency; and the third group were all adults whose native language is Japanese; the fourth group were adults whose native language is English. These participants read the context with different continuity separately; the result showed that native-language readers paid more attention to high-level process, i.e. reasoning, association and etc.., at the same time they used different method to handle the context with different continuity.

Upton notes that L2 readers may think in L1 and use L1 as a strategy to help comprehend an L2 text [18-19]. Later, he investigated how 10 native speakers of Chinese and 10 native speakers of Japanese used their L1 in the L2 reading process. In the study, it is found that students of lower L2 proficiency tend to use more $\mathrm{L} 1$ in the $\mathrm{L} 2$ reading process and students of higher 12 proficiency tend to use their L1 more effectively to help them comprehend.

Seng \& Hashim investigated the L1 use in L2 group reading process with think-aloud method [20]. The researchers organized four participants in one group and asked them read the English context and think it out loudly. The research found that all the participants use L1 thinking in L2 reading process, and $30 \%$ strategies were conducted with native language.

Wu \& Wang who adopted both think-aloud method and retrospective interview to study the relation between L1 thinking and L2 thinking in the L2 reading progress of 21 Chinese college students [21]. The participants were divided into three groups according to their English proficiency: high-level group, moderate-group and low-level group. The researchers used the think-aloud method to investigate the comprehension and cognition process of students' English reading process, then they asked the students to interpret part of the content of think-aloud protocols by retrospective interview. The researchers found with the improvement of English proficiency, the ratio of using L1 thinking to comprehend was decreasing. However, L1 helped reading comprehension more. The study also found translation strategy was commonly used by Chinese English learners, the readers used their native language to handle the vocabulary and sentences, also, used native language to presuppose, verify and monitor their reading content and action.

Wang Yenui explores the differences between more successful and less successful EFL readers in their comprehension performance and abilities to use reading strategies in interaction with English texts through thinking aloud while reading in pairs. The findings drawn from analysis of the reading scores and think-aloud protocols of 
the most successful pair and the least successful pair indicated that the most successful had scored higher on the comprehension questions and had performed think-aloud reading better than the least successful. Key differences characterizing the best pair from the weakest pair in this study were found to lie in readers' effective reading strategy use, sufficient linguistic knowledge and background knowledge, conscious monitoring of comprehension, and constant integration of textual meaning [22].

\section{Research Design}

\subsection{Participants}

The participants in this study were 12 college students from Dalian Maritime University. The age range of these participants was 19-21 years old. Among them, four have passed CET6, four have passed CET4 and four have not passed CET4. Their educational background was homogeneous and before they were accepted, these participants were examined whether they were articulate which may be required in the think-aloud process of this study.

According to their English proficiency, the 12 non-English major participants were divided into three groups, the students in advanced-level group all passed CET6, those in intermediate-level group all passed CET4 and in low-level group none has passed CET4.

\subsection{Instruments}

The study will adopt the think-aloud protocol as the data collection instrument to test whether there are some differences of L1's involvement in L2 reading of students at different levels. The think-aloud method was employed in this study to elicit the verbal reports of what was going on in the reader's mind during the second language reading comprehension process.

The reading articles used in think-aloud process were selected from CET4 reading comprehension. Every participant had to read the CET4 article independently. In addition, the author has confirmed that all the participants hadn't read the text before.

Table 1 shows the number of words and sentences in the article:

Table 1. The Number of Words and Sentences in the Article.

\begin{tabular}{lll}
\hline Reading article & Words No. & Sentences No. \\
\hline CET4 & 508 & 17 \\
\hline
\end{tabular}

\subsection{Procedures}

There are two stages in data collection procedures: think-aloud training process and reading process.

The participants in the study were given training in think-aloud prior to data collection; general instructions for the experiment were orally provided to them in their native language. The training sessions were deemed important so as to equip the students with the necessary skills needed so that they were able, willing and comfortable to think aloud while reading. These training sessions were conducted in a classroom. It took 25 minutes for researcher to demonstrate the training contents, and, it took 15 minutes for all the participants to accomplish a trial think-aloud task which material used was different from that used in the formal thinking-aloud process.

After the training and the practice sessions, the participants were asked to verbalize whatever they were thinking as their thoughts naturally came to mind while reading and doing the assigned tasks such as comments on language, content, task or whatever they associate with them. They were also reminded that pause and silence could not take much time when they thinking aloud. Think-aloud experiment was conducted one participant by one participant in a classroom, the whole reading and think-aloud was audio-taped. The audio-recorded think-aloud and verbal discourses by the participants were transcribed and the protocols were then analyzed in order to answer the research questions.

\section{Results and Discussion}

The paper is inclined to indicate the difference of L1 thinking in L2 reading process when English learners at different levels read the same text.

Firstly, the quantity of Chinese words involved in L1 reading activities was counted in this research which can indicate L1 involvement in 3 groups' reading activities. For example, we could be informed that L1 thinking involved in meaning-based reading activities of group A is 1746 Chinese words when they are reading CET4 text. L1 thinking was used by all the students at different levels.

Moreover, according to the protocols analysis, the researcher found that readers at different levels apply L1 thinking in their L2 reading process dissimilarly, which mainly focused on two differences:

Firstly, from the think-aloud protocols the researcher observed that the main difficulty in sentence understanding obstacles was the limitation of vocabulary size. As for understanding of vocabulary by using L1 thinking, readers usually translate the English words into Chinese ones for extracting the word meaning. The readers could pay more attention on semantic relation within words in reading comprehension if they are familiar with vocabulary in text. If not, or they could not get clues from the context, they would fail to comprehend the meaning of sentence. Comparatively speaking, readers in low-level and intermediate-level group had more vocabulary obstacles than readers in advances-level group. When reading the CET4 material, for several times the readers in low-level and intermediate-level group encountered sentence understanding obstacles (comprehension barriers, omission of information and skimming) because of the limitation of their vocabulary, relatively poor L2 reading efficiency is the main factor leading to their heavy reliance on L1. But readers in advanced-level group did not, for them L1 usually plays a supportive and efficient role; they tend to use more $\mathrm{L} 1$ to associate in the process of $\mathrm{L} 2$ reading.

Following are extracted from the think-aloud protocols of 
two participants in different group. Think-aloud protocol I is from participant in the low-level group, and Think-aloud protocol II is from participant in the high-level group. They adopted different understanding style to read same sentence group when reading CET4 material.

Example 1:

(Original text) This violation of concentration, silence, solitude goes to the very heart of our notion of literacy; this new form of part-reading, of part-perception against background distraction, renders impossible certain essential acts of apprehension and concentration, let alone that most important tribute any human being can pay to a poem or a piece of prose he or she really loves, which is to learn it by heart.

(Think-aloud protocol I)

䍐，下一句，...哇，这句里面好像有几个词不认识，那 就先慢点读吧， the violation of concentration,... 恩， violation 好像是妨碍的意思吧, 这里说对 concentration, 安 静, 还有 solitude 的妨碍吗? ...concentration 好像是集中 注意的意思的, ...(5') solitude 是什么? 有点眼熟, 但是还 是不清楚, 那就看看后面先, goes to the very heart of our notion of literacy, 是说对集中注意, 安静, 还有 solitude 的妨碍成为了我们对阅读概念的核心部分。嗯, 继续, 这 种新形式的 part-reading, of part-perception against 背景的 distraction,... (6') 哎呀, 这句怎么这么难读, 好几个不认 识的, 什么意思呢? ... part-reading 可能是部分阅读, 然 后与背景 distraction 相反? ...不懂, 到底什么意思呢? 再 看下去吧, ... renders?...这个也不知道是什么, 恩, 可能 的 renders 确实、基本的理解和集中行为? ...(6 (6')哎呀, 这 些词看不懂, 翻译不上来这句话什么意思, 最后一句吧, let alone 就是说更别说最重要的 tribute?... 有点像贡献那个 词, 不知道是不是意思一样, 任何人能够去读一个诗歌或 者文章,或者是这个人真正喜欢的, which is learn it by heart. 就是记在心里, 用心学吧。太难了, 都不理解, 还是先看 下面的吧。

(Think-aloud protocol II)

哦, 刚开始读第一句, 单词倒是基本认识, 可是意思感 觉有点抽象, 连不到一起啊! ... violation of concentration 指的是什么还不是很清楚。不过我先不能着急, 看下下面 的也许就能明白吧！再读下去看看, ...(5') 恩, 通过下一 句的前几个词 this new form of part-reading 觉得头脑里好 像有个大概的看法了, ...恩, 原来在讲一种新的阅读方式! 有了这个大概的了解以后, 突然感觉后面的内容好读多了, 不像第一眼看上去那么不容易理解了, 意思也似乎明了了 些！但是还是有个别词特不好理解：比如这里这个 tribute。...再回头重新看下前面的句子, 把意思贯穿下吧... 原来后面在讲这种心得阅读方式的缺点和不足啊! 前后联 系, 整段的意思就都明白多了, 然后继续看后面的。

The think-protocols analysis showed that readers at different levels apply L1 to deal with information in sentences dissimilarly. From Think-aloud protocol I it could be found that reader in low-level group paid more attention to the semantic understanding of uncertain vocabulary and focused on the unknown words instead of looking into the holistic meaning of that sentence. From Think-aloud protocol II, reader in the advanced-level group laid stress on the interrelation between unknown vocabulary and the context and focused on the semantic relation of the whole sentence-group.

Secondly, it is found that readers in low-level and intermediate-level group usually read almost every sentence in detail regardless of its main and secondary and they all used to achieve understanding and cognitive process of sentences by translating them into L1; while readers in advanced-level group tend to neglect the sentences have no association with the testing questions they think. That is to say, participants in advanced-level group usually read several of sentences and skim or scan information which is regarded as not useful and import while participants in low-level and intermediate-level group usually read almost all the sentences and try to comprehend them all regardless of their importance.

Generally speaking, the researcher found that L1 thinking facilitate L2 reading process. Students have been found to rely on L1 use in the process of comprehending L2 texts and the degree of such reliance is related to the level of proficiency [6, 18]. With the increase in their English proficiency, the reader's reliance on Chinese is more supportive and effective [21]. The differences of L1 used by learners at different level in each reading activities indicate that when readers are reading the L2 text, L1 thinking plays different roles.

\section{Conclusion}

L2 readers have been found to rely on L1 use in the process of comprehending L2 texts and the degree of such reliance is related to the level of proficiency. Cook argues that exclusive use of the target language in second or foreign teaching is not theoretically justified and does not lead to maximum language learning [2]. Teachers or students maximize their target language use, without avoiding L1 "at all costs". College students, particularly those of lower proficiency, usually lack the vocabulary and ability to express or verbalize their thoughts confidently, clearly and accurately. Therefore, the teachers should take a tolerant attitude towards native language, that is, the teachers encourage more of L2, but a little reliance on L1 is also acceptable or understandable. For example, when students have difficulties in expressing their ideas in English classes, the teachers can permit L1 use in order to get new ideas or complete some advanced tasks, then with the help of the teachers and other students, they may reorganize their thoughts in English.

\section{References}

[1] Cohen, A. D. (1995). In which language do/should multilinguals think? Language, Culture and Curriculum 8; 99-133J. Clerk Maxwell, A Treatise on Electricity and Magnetism, 3rd ed., vol. 2. Oxford: Clarendon, 1892, pp. 6873 .

[2] Cook, V. J. (1992). Evidence for multicompetence. Language Learning 42: 557-91.

[3] Ellis, R. (1994). Understanding Second Language Acquisition. Oxford: Oxford University K. Elissa, "Title of paper if known," unpublished. 
[4] Dole, J. A., Duffy, G. G., Roehler, L. R., \& Pearson, P D. (1991). from the Old to the New: Research on Reading Comprehension Instruction. Review of Educational Research, 61, 239-264.

[5] Stern, H. (1992). Issues and Options in Language Teaching. Oxford: Oxford University Press.

[6] Kern, R. G. (1994). The role of mental translation insecond language reading. Studies in Second Language Acquisition 16: 441-61.

[7] Cohen, A. D. (1998). Strategies in Leaning and Using a Second Language.

[8] Gass, S. M. \& Selinker, L. (1983). Language Transfer in Language Learning. Issues in Second Language Research. Newbury House Publishers, Inc.

[9] Faerch, C. \& G. Kasper. (1987). Introspection in Second Language Research. Clevendon, Philadelphia: Multilingual Matters Ltd.

[10] Auerbach, E. R. (1993). Reexaming English only in the ESL Classroom. TESOL Quarterly, 27 (1).

[11] Polio, C. (1994). Comments on Elsa Roberts Auerbach's "Reexaming English only in the ESL Class Reacts". TESOL Quarterly, 28 (1), 153-161.

[12] Matsumoto, K. (1993). Verbal-report data and introspective methods in second language research: State of the art. RELC Journal, 24, 32-59.

[13] Vygotsky, L. S. (1978) Mind in society: The development of higher psychological processes. Cambridge, MA: Harvard University Press. (Original work published in 1934).
[14] Cummins, J. (1980). Psychological Assessment of Immigrant Children: Logic or Intuition? Journal of multilingual and multicultural development, 1, 97-111.

[15] Cummins, A. (1986). Intentional learing as a principle for ESL writing instruction: A case study. TESL Canadian Journal. Speciss.

[16] Guo Chunjie \& Liu Fang. (1997). A Dynamic Research into L1 Influence on L2. Modern Foreign Languages, (2): 30- 38.

[17] Horiba, Y. (1996). Comprehension processes in L2 reading. Studies of Second Language Acquisition, 18, 433-475.

[18] Upton, T. A. (1997). First and second language use in reading comprehension strategies of Japanese ESL students. TESL-EJ 3: 7-17.

[19] Upton, T. A. (1998). "Yuk, the skin of insects!" Tracing sources of errors in L2 reading comprehension. Journal of College Reading and Learning 29: 5-20.

[20] Seng, G., \& Hashim, F. (2006). Use of L1 in L2 reading comprehension among tertiary ESL learners. Reading in a Foreign Language, 18 (1), 29-54.

[21] Wang Wenyu \& Wen Qiufang. (2002). L1 use in the L2 composing process: An exploratory study of 16 Chinese EFL writers. Journal of PLA University of Foreign Languages, (4): 64-67.

[22] Wang, Yenhui. (2016). Reading Strategy Use and Comprehension Performance of More Successful and Less Successful Readers: A Think-Aloud Study. Educational Sciences: Theory and Practice, 16 (5), 1789-1813. 